\title{
Geotechnical Hazards and Environmental Changes Threatening the Sphinx Avenue and the Project of Luxor: Open Museum
}

\author{
Ibrahim A. Alnaser ${ }^{1}$, M. M. Abuzeid ${ }^{2}$, A. F. Gelany, ${ }^{3, *}$ Ahmed H. Backar ${ }^{1,4}$, Mohammed Y. Abdellah ${ }^{1,5}$ \\ ${ }^{1}$ Department of Mechanical Engineering, College of Engineering and Islamic Architecture, Umm Al-Qura University, Makkah, KSA \\ ${ }^{2}$ Department of Civil Engineering, Faculty of Engineering, South Valley University, Qena, Egypt \\ ${ }^{3}$ Department of Restoration, Faculty of Archaeology, Luxor University, Egypt \\ ${ }^{4}$ Department of Production Engineering, Faculty of Engineering, Alexandria University, Egypt \\ ${ }^{5}$ Department of Mechanical Engineering, Faculty of Engineering, South Valley University, Egypt
}

Received November 16, 2020; Revised December 28, 2020; Accepted January 20, 2021

\section{Cite This Paper in the following Citation Styles}

(a): [1] Ibrahim A. Alnaser, M. M. Abuzeid, A. F. Gelany, Ahmed H. Backar, Mohammed Y. Abdellah, "Geotechnical Hazards and Environmental Changes Threatening the Sphinx Avenue and the Project of Luxor: Open Museum," Civil Engineering and Architecture, Vol. 9, No. 1, pp. 85 - 90, 2021. DOI: 10.13189/cea.2021.090107.

(b): Ibrahim A. Alnaser, M. M. Abuzeid, A. F. Gelany, Ahmed H. Backar, Mohammed Y. Abdellah (2021). Geotechnical Hazards and Environmental Changes Threatening the Sphinx Avenue and the Project of Luxor: Open Museum. Civil Engineering and Architecture, 9(1), 85 - 90. DOI: 10.13189/cea.2021.090107.

Copyright $\odot 2021$ by authors, all rights reserved. Authors agree that this article remains permanently open access under the terms of the Creative Commons Attribution License 4.0 International License

\begin{abstract}
The simulation of the ceremonies of the Pharaonic celebrations in the Sphinx's Avenue is one of the most important Millennium Goals for Luxor Governorate, which is supported by UNESCO until 2022. All sections of the road were constructed during the eighteenth to thirty dynasty period. Some attachments have been added to the road in different periods, such as wine presses used in major ceremonies that were held on the road such as ophthalmic feasts and beautiful valley feasts, etc. The road has been neglected across different periods, and more than 4 meters of sand, silt and Nile clay were accumulated in different sites. Excavations began on the road in the late 1940s, until work was halted after the January Revolution due to lack of funds. The aim of these study is examination of the geotechnical properties of the project to Facing challenges that led to bury and deterioration of the road and also to develop sustainable geotechnical solutions to resist threats and risks. Scanning Electron Microscope was used to investigate the six samples of soil under the six sections of the road to study the hazards due to the impaction of clay minerals which threaten the Sphinx Avenue and The Project of Luxor, Open Museum. Basic properties test of the foundation soils illustrated the expansive properties which often were classified moderate. Expansive
\end{abstract}

properties are one of the factors of the evaluation of the hazard besides the relevance of the construction to environmental changes and sustainability agents.

Keywords Geotechnical Hazards, The Sphinx Avenue, Luxor Open Museum Project

\section{Introduction}

There is evidence to suggest that Queen Hatshepsut was the first one who constructed the Sphinxes Avenue extends, which expand from Luxor to Karnak Temples is about 2700 m with 18th Dynasty by 1200 sculptures of sphinxes [1].There are a lot of kings who have constructed parts of this avenue such as Amenhotep III, King Tutankhamun, Nectanebo, ... Etc. [2, 3]. During centuries after the pharaonic period, several parts of ancient Luxor (Thebes) have been buried by nearly 15 meters of clay, rubbish, silt, and sand [4]. Several environmental factors are responsible for this phenomenon such as Ancient Arab nomadic culture, Periods of foreign occupation and wars, Flood of the Nile until the construction of the High Dam, 
Ancient beliefs and ruin theory, Neglect of the historical buildings until the advent of the French campaign [5]. Figure 1 shows accumulated soils and the cultural of the local children about heritage sites from 2009 [6].

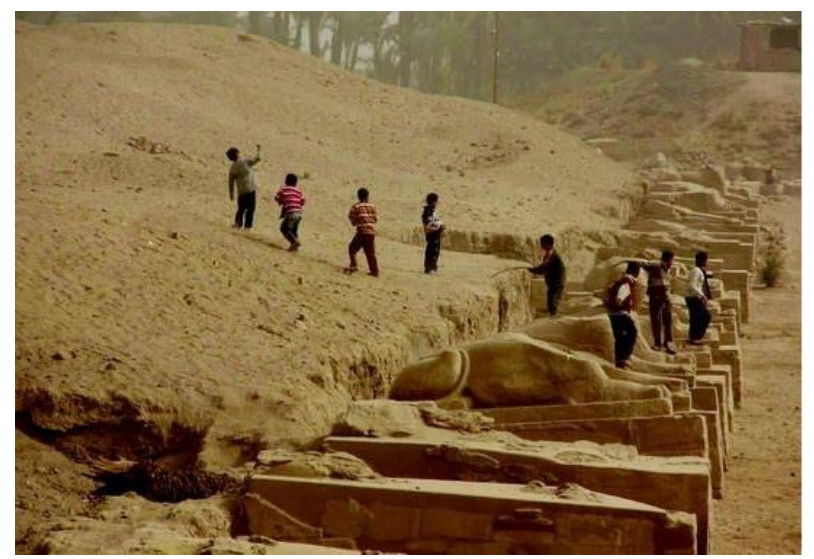

Figure 1. Accumulated soils and the local children played inside heritage sites section five of sphinx avenue (from 2009 after [7])

Some of the environmental threats caused unwanted consequences of trying to turn Luxor into an open museum such as providing outdoor areas for sightseeing, lack of knowledge regarding the differences between the 'open museum' concept, absence of geotechnical and environmental studies, unclear mission for the locals and absence integration work between the scenario of 'open museum' and the local and vernacular cultures $[6,8,9]$. Increased population causes a negative effect due to urban development in proximity to a World Heritage Site, so It must be found a suitable strategy to implement Heritage Impact Assessment (HIA) in Egypt. Luxor open museum project aims to rectify the urban planning mistakes in the past by creating attractive places where people will want to live and work in the future [7, 10,11].

One of the studies about sphinx's avenue interested only these tasks; (a) Acquisition and upgrade of the database. (b) Management of quantitative data and information. (c) using geographic information systems (GIS). (d) Spatial analysis and simulation. This study was unintegrated due to the absence of major axis such as the local, restoration integrated approach and sustainability $[12,13]$. The clay fraction in soil samples predictably influences the mass behavior of the soil base for engineering use [14], even when present in a small proportion of each sample, so as to achieve the aims of these study, some investigations must be carried out such as basic properties of soils, and Scanning Electron Microscope (SEM) of the soil foundation for the six detected sections of the Sphinx's Avenue, these investigations occurred to evaluate the role of soil foundations in the sustainability of the conservation processes. The six sections of the Sphinx's Avenue are; section one from Luxor temple to Church of the Virgin Mary, the second section from Church of the Virgin Mary to Luxor Museum Square, section three from Luxor
Museum Square to Egypt Public Library, section four from Egypt Public Library to crossroads, section five from crossroads, section six up to mutt temple.

The objective of the present study is to explain and test foundation soils of the Sphinx Avenue, which are at a lower level than the level of the surrounding streets and thus are exposed to environmental risks, so this examination of the geotechnical properties is one of the aims of study of the project to Facing challenges that led to bury and deterioration of the road and also to develop sustainable geotechnical solutions to resist threats and risks.

\section{Foundation Soils}

Six undisturbed fresh samples were obtained by open excavation from foundation soils of the six sections of the road classified by the ministry of antiquate (about $15 \mathrm{~cm}$ depth). Samples were invested by using Scanning Electron Microscope (SEM) to identify the type of soils and textures of soils at the central laboratory of South Valley University $[15,16]$. Basic properties of foundation soils, Modified Proctor test and classified of soils were used for determinating the expansive soil and its role in the deterioration of the heritage sites [17-19], basic properties test carryout at environmental and construction studies laboratory, The High Institute of Engineering and Technology, Luxor, Egypt.

\subsection{Scanning Electron Microscope Analysis}

Samples were examined using a JOEL JSM-35C scanning electron microscope (SEM) equipped with a dispersive $\mathrm{x}$-ray card(EDX) detector available at the Central Lab, South Valley University, Egypt. Figure 2 shows crushing and milling of particles under the old police station. Figure 3 shows SEM of the sample from section tow illustrates fissure development of marginalization of smectite-dominated mudstone.

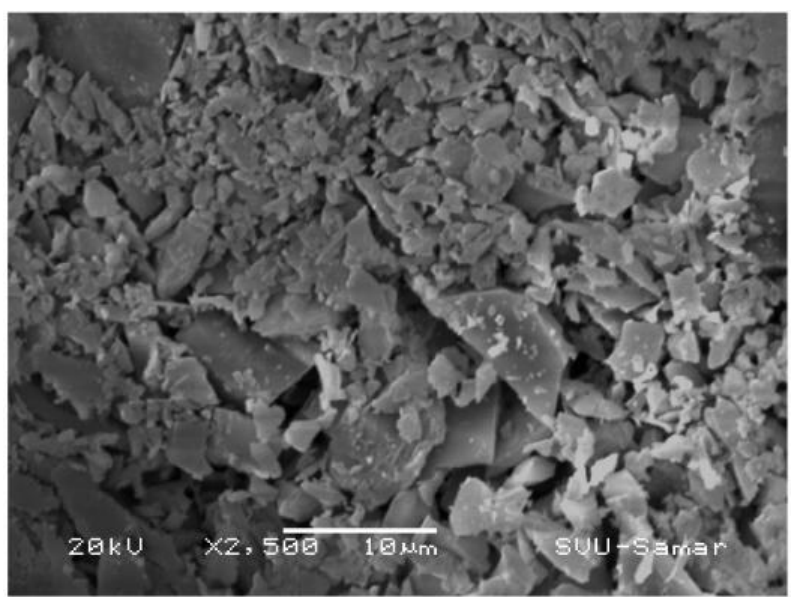

Figure 2. SEM of sample from section one 


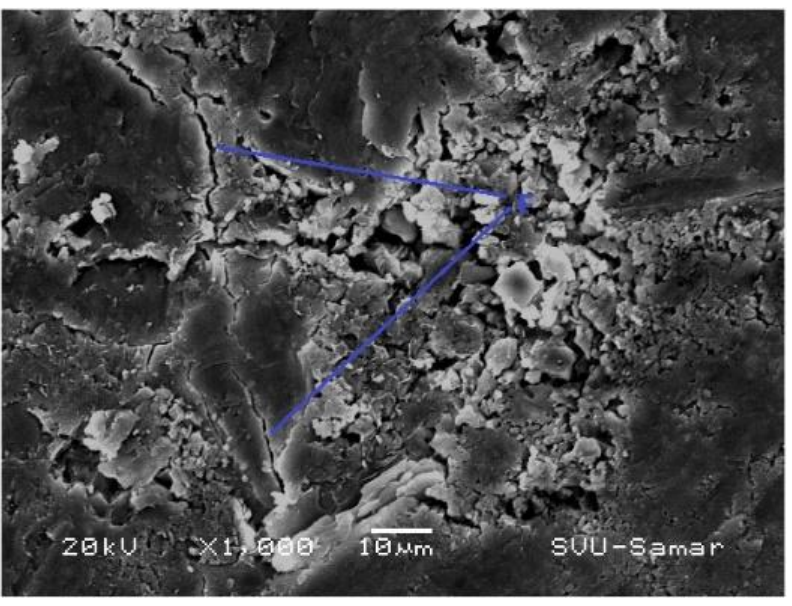

Figure 3. SEM of a sample from section two; (F) Fissure development of marginalization of smectite-dominated mudstone.

Section three and section four are characterized by clay minerals such as illite (i), smectite (sm), kaolinite, and chlorite due to Sheikh Musa old canal, with the appearance of environmental minerals as dolomite (d) and calcite (ca) between sand particles (sd). Figures 4 and 5 show SEM of clay and environmental minerals.

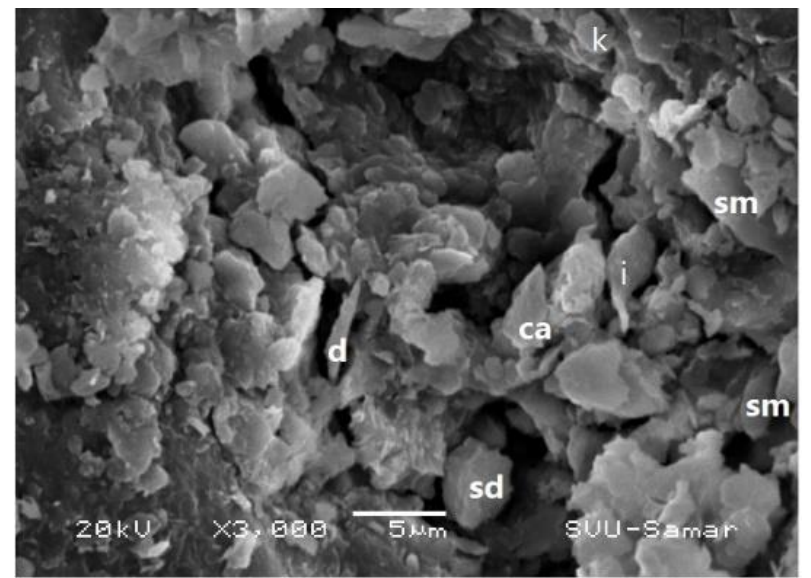

Figure 4. SEM of a sample of section three.

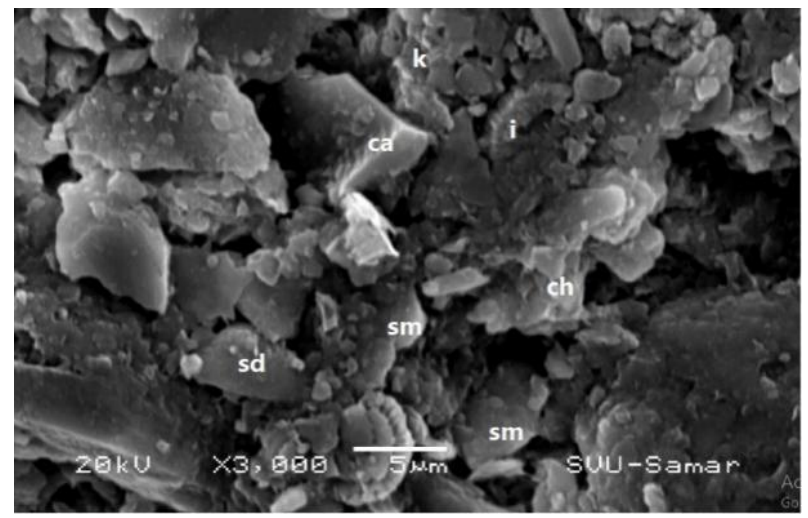

Figure 5. SEM of sample of section four

Figure 6 shows the microstructure of mudstone bearing Smectite menials under rubble from section five as shown in figure 1. The mineralogy of the selected soil sample from section six is shown in figure 7. shows SEM of the major clay mineral types obtained are kaolinite, smectite, and illite. The appearance of minerals such as quartzite, dolomite, and calcite is due to calcic paleoenvironments.

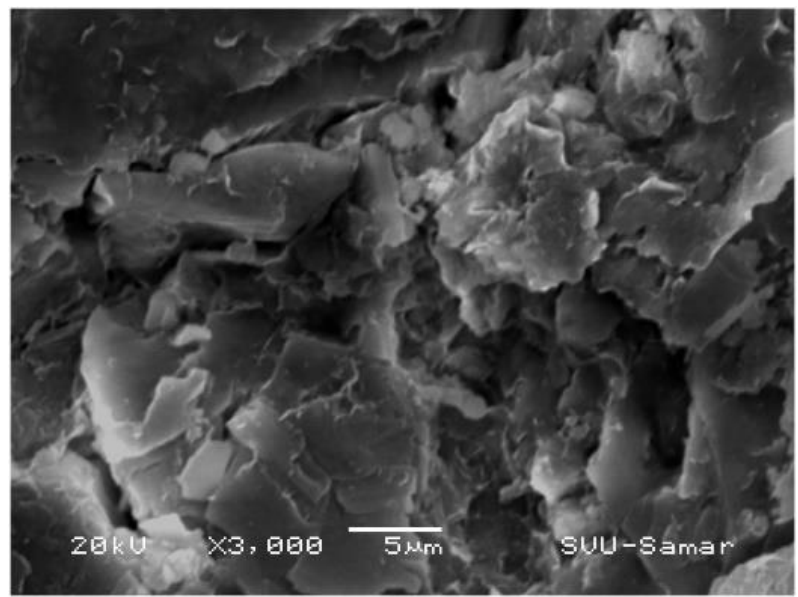

Figure 6. SEM of a sample from section five illustrate microstructure of mudstone bearing Smectite menials

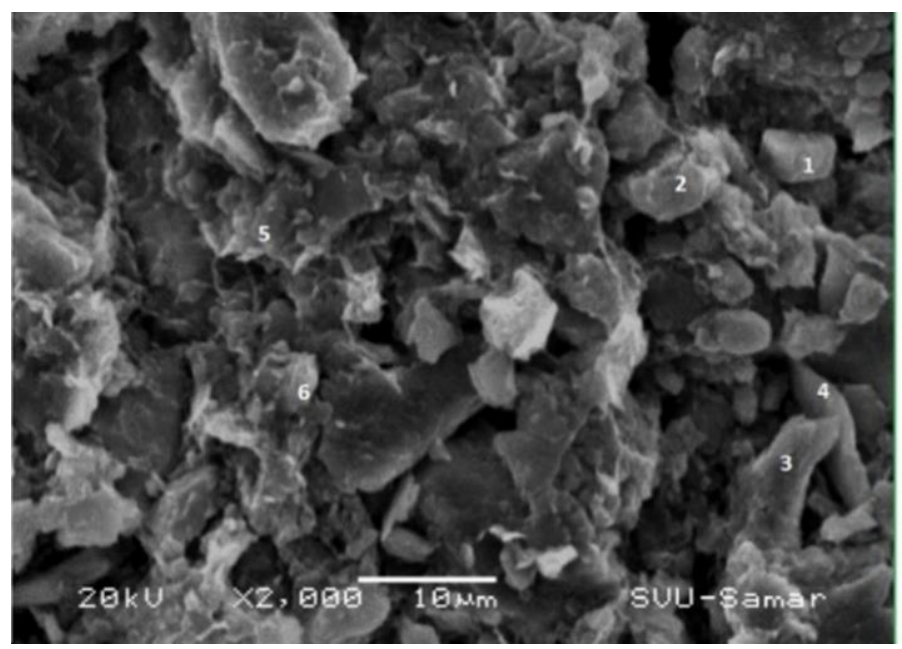

Figure 7. SEM of clay mineral from section six

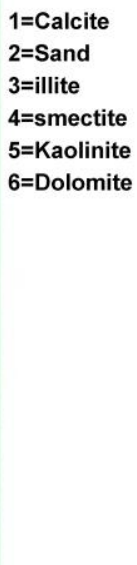

2=Sand

4=smectite

$5=$ Kaolinite

6=Dolomite 


\section{Results and Discussion}

\subsection{Basic Properties of Samples}

According to the ASTM (American Society for Testing and Materials), all samples were tested. Basic properties of samples such as;

$1 \quad$ Plastic Limits (ASTM D854)

2 Liquid Limits Tests (ASTM 4318)

3 Particle Size Distribution (mechanical method and hydrometer technique) (ASTM D422)

4 Specific Gravity (ASTM D4546)

$5 \quad$ Swell Potential tests (ASTM D421)

All tests were carried out. Figure 8 shows the textures of the samples according to the Liquid limit and Plasticity index, four samples in the clay zone, and two samples in the shale zone. Figure 9. shows particle size distribution of the utilized expansive soil, all samples in moderately expansive soil zone.

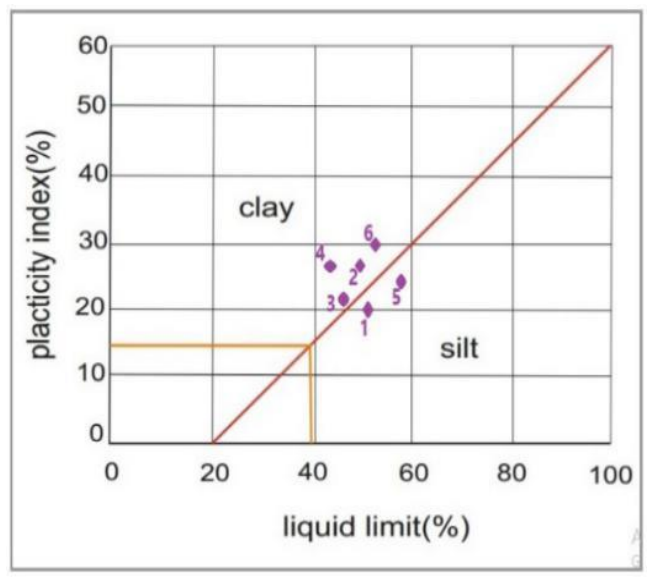

Figure 8. The textures of the samples according to the Liquid limit and Plasticity index

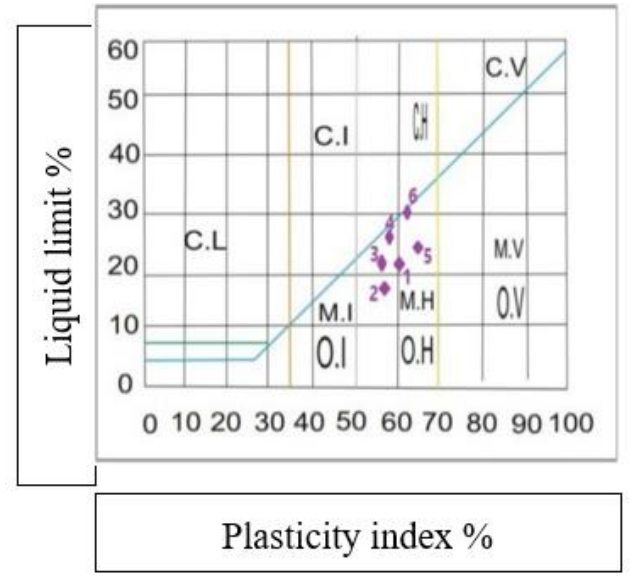

Figure 9. The particle size distribution of the utilized expansive soil $(\mathrm{CH}$; clay, high plasticity. $\mathrm{OH}$; organic clay. $\mathrm{MH}$; inorganic silts, micaceous. CL; clay low plasticity. OL; organic silty clay. ML; clayey fine sands)

\subsection{Classification of the Samples of Soils Based on Swelling Potential}

According to the values of swell potential which are carried out by standard roles, the result of classification systems of expansive soils concluded as; tow samples are highly expansive soils where other four samples of are considered as medium expansion. Figure 10 shows a classification chart based on swelling potential. The A-line generally separates the siltier materials from claylike materials, and the inorganics from the organics [20].

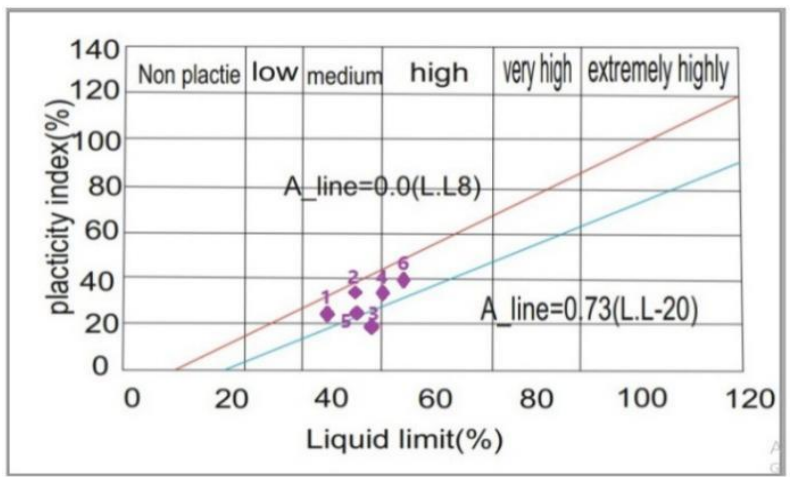

Figure 10. Classification chart based on liquid limit and plastic index

\subsection{Unconfined Compression (UC) Test}

Six undisturbed samples are obtained from the six section of the sphinx avenue using the unconfined compression (UC) test due to these advantages; (a) (UC) test is one of simplest and easiest tests for detecting a quick estimate of the shear strength of cohesive soils. (b) (UC) test is used to determine the consistency of saturated cohesive soils and clays. (c) The compressive strength values of soil in both redesigned and intact condition are obtained using (UC) test, according to the protocol of the California Test 221, March 2000" the six unsaturated samples which obtained from the different six sections by tube sampling. the testing procedures are;

i). the specimen was Put on the base of a holder and set the holder on the compression device.

ii). Drop down the compaction piston just before specimen push the rod

iii). Read the strain rate

iv). begin the test.

Resume $20 \%$ strain is reach or the load values begin to decrease. Figure 11 shows a classification chart based on clay content and activity. Activity $=\mathrm{IP} / \mathrm{C}(\mathrm{IP}=$ plasticity index, $\mathrm{C}=$ clay content). Figure 11. Shows a classification chart based on clay content and activity. Activity $=\mathrm{IP} / \mathrm{C}$ (IP= plasticity index, $\mathrm{C}=$ clay content) [21-23]. 


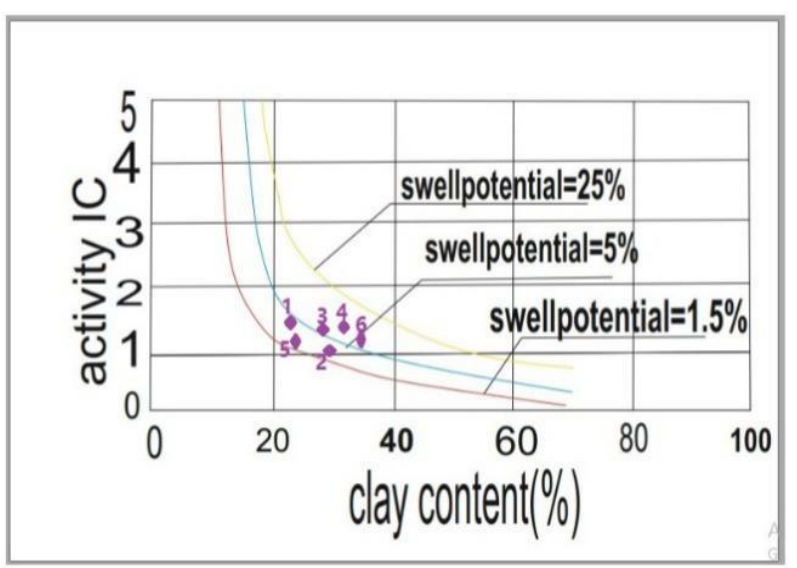

Figure 11. The classification chart is based on clay content and activity.

\section{Conclusion and Recommendation}

Sphinx Avenue was approximately semi-completely covered by tons of Nile silty clays and recently accumulated deposits. Construction was also built over parts of it, such as churches, the People's Club, the old police station, and others, which the project manager is working to remove. Therefore, the first precautions that shall be considered are the assessment of the surrounding environmental factors so that the road does not face deterioration and backfilling again. Parts of both sides of the road should be removed so that the road and the city level become one surface level. Tests using the scanning electron microscope showed the presence of clay minerals characterized by expansion properties. This is an additional challenge, especially with the low level of the road that can be converted into a waterway for the expected torrents due to climatic changes. When measuring the basic properties of six samples from six sectors through the ram, confirm the presence of the extending properties of the base soil. This is an additional challenge. It is possible to get out of this study with a recommendation, that the Sphinx Avenue and The Project of Luxor; Open Museum shall be in one surface-level over a good Infrastructure which match with sustainability and climatic changes.

\section{Conflicts of Interest}

The authors declare no conflict of interest.

\section{REFERENCES}

[1] A. A. Basheer, A. M. Abdel-Motaal, A. El-Kotb, A. I. Taha, and M. A. Abdalla, "Tracing of the Avenue of the Ram-Headed Sphinxes Remains Using Geophysical Investigations, Luxor., Egypt," International Journal of
Geosciences, vol. 2014, 2014. DOI:10.4236/ijg.2014.58070.

[2] M. Boraik, "The Sphinxes Avenue Excavations to the East Bank of Luxor," in Sustainable Conservation and Urban Regeneration, ed: Springer, 2018, pp. 7-31 https://link.springer.com/chapter/10.1007/978-3-319-65274 $-0 \_2$.

[3] E. S. Hesham and I. Baller, "Changing Perspectives on Responsible Heritage Site Management: The Case of Luxor City, Egypt," História: Questões \& Debates, vol. 66, pp. 141-165, 2018 DOI:10.5380/HIS.V66I1.57407Corpus ID: 165695890 .

[4] R. M. Rombolà, "The GIS for Urban Analysis and Risk Map of Archaeological Site: The Case of Sphinxes Avenue in Luxor," in Sustainable Conservation and Urban Regeneration, ed: Springer, 2018, pp. 163-176. https://link.springer.com/chapter/10.1007/978-3-319-65274 $-0 \_10$.

[5] M. Giambruno and R. Gabaglio, "Beyond Ancient Egypt. Preservation and Valorisation of the Sphinxes Avenue in Luxor and Its Urban Context," in Sustainable Conservation and Urban Regeneration, ed: Springer, 2018, pp. 139-162 https://link.springer.com/chapter/10.1007/978-3-319-65274 -0_9.

[6] A. Abulnour, "Acupuncturing Luxor: Reinventing the Open Museum Concept," in Sustainable Conservation and Urban Regeneration, ed: Springer, 2018, pp. 107-121. https://link.springer.com/chapter/10.1007/978-3-319-65274 $-0 \_7$.

[7] G. Kamar and T. Ismail, "Urban Regeneration Challenges of Heritage Cities Using GIS;(Luxor City Case Study)," in 1st International Conference on Towards a Better Quality of Life, 2017 http://dx.doi.org/10.2139/ssrn.3171835.

[8] M. Moscatelli, "The Project for the Sphinx Alley in Luxor. Notes About the Methodological Approach, Between Modalities of Analysis and Operative Criterias," in Sustainable Conservation and Urban Regeneration, ed: Springer, 2018, pp. 67-81 https://link.springer.com/chapter/ 10.1007/978-3-319-65274-0_5.

[9] E. Silvestri, "Sustainable Tourism and Urban Planning," in Sustainable Conservation and Urban Regeneration, ed: Springer, 2018, pp. 83-106https://link.springer.com/chapter /10.1007/978-3-319-65274-0_6..

[10] M. Boriani, "Urban Restoration, Cultural Heritage and International Cooperation," in Sustainable Conservation and Urban Regeneration, ed: Springer, 2018, pp. 123-137 https://link.springer.com/chapter/10.1007/978-3-319-65274 $-0 \_8$.

[11] M. G. Folli, "Archelogy, Architecture, City. Luxor Between Past and Future," in Sustainable Conservation and Urban Regeneration, ed: Springer, 2018, pp. 41-66 https://link.springer.com/chapter/10.1007/978-3-319-65274 $-0 \_4$.

[12] G. Magli, "Architecture, Astronomy, and Sacred Space: The Case of the Avenue of the Sphinxes," in Sustainable Conservation and Urban Regeneration, ed: Springer, 2018, pp. 33-39 https://link.springer.com/chapter/10.1007/978-3319-65274-0_3.

[13] M. El-Gohary and M. Redwan, "Alteration parameters 
affecting the Luxor Avenue of the Sphinxes-Egypt," Science of The Total Environment, vol. 626, pp. 710-719, 2018. doi.org/10.1016/j.scitotenv.2017.12.297.

[14] S. Daramola, S. Malomo, and Y. Asiwaju-Bello, "Premature failure of a major highway in southwestern Nigeria: the case of Ipele-Isua highway," International Journal of Geo-Engineering, vol. 9, p. 28, 2018 https://link.springer.co $\mathrm{m} /$ article/10.1186/s40703-018-0096-9.

[15] İ. Met, H. Akgün, and A. Türkmenoğlu, "Environmental geological and geotechnical investigations related to the potential use of Ankara clay as a compacted landfill liner material, Turkey," Environmental Geology, vol. 47, pp. 225-236, 2005 DOI 10.1007/s00254-004-1147-4 Environmental Geology (2005) 47:225-236.

[16] A. Rapacz-Kmita, E. Stodolak-Zych, M. Ziabka, A. Rozycka, and M. Dudek, "Instrumental characterization of the smectite clay-gentamicin hybrids," Bulletin of Materials Science, vol. 38, pp. 1069-1078, 2015 https://link.springer.c om/article/10.1007/s12034-015-0943-7.

[17] M. Y. Abdellah, A. Gelany, A. F. Mohamed, and A. B. Khoshaim, "Protection of limestone coated with different polymeric materials," American Journal of Mechanical Engineering, vol. 5, pp. 51-57, 2017 DOI:10.12691/ajme-52-3.

[18] M. Y. Abdellah, A. Gelany, and M. M. A. Zeid,
"Compressive and Failure Strength of Sand Stone with Different Strengthen Materials," American Journal of Materials Engineering and Technology, vol. 2, pp. 43-47, 2014 DOI:10.12691/materials-2-3-4.

[19] A. F. Y. Gelany, M. M. A. Zeid, M. S. Abd El-Sadek, and A. M. Mansour, "Evaluation of the Expansive Esna Shale and Its Role in the Deterioration of Heritage Buildings at West Bank of Luxor," Journal of Geoscience and Environment Protection, vol. 7, pp. 24-37, 2019 DOI: 10.4236/gep.2019.78002.

[20] Manjate, V. A., Issufo, Z., \& Magenge, A. L. (2020). Evaluation of clay soils from Manjacazi district (Mozambique) as potential raw material for the ceramic industry. Heliyon, 6(10), e05189.

[21] Galvín, A. P., López-Uceda, A., Cabrera, M., Rosales, J., \& Ayuso, J. (2020). Stabilization of expansive soils with biomass bottom ashes for an eco-efficient construction. Environmental Science and Pollution Research, 1-14.

[22] Ramadhan, M. A. (2020, September). Improvement of Expansive Soils Stabilized with Rice Husk Ash (RHA). In Journal of Physics: Conference Series (Vol. 1625, No. 1, p. 012006). IOP Publishing.

[23] N. S. Korim, M. Y. Abdellah, M. Dewidar, and A. M. Abdelhaleem, "Crushable Finite Element Modeling of Mechanical Properties of Titanium Foam," 2015. 